\title{
Analisis Nilai Tambah dan Efisiensi Usaha Tape Ketan pada Industri Rumah Tangga Tape Ketan di Desa Sungai Karias Kecamatan Amuntai Tengah Kabupaten Hulu Sungai Utara
}

\section{(The Added Value Analysis and Business Efficiency of Sticky Tape at Home Industry Sticky Tape In Sungai Karias Village Amuntai Tengah District Hulu Sungai Utara Regency)}

\author{
Azwar Saihani $^{1)}$ \& Siti Hapizah ${ }^{2)}$ \\ Program Studi Agribisnis, Sekolah Tinggi Ilmu Pertanian Amuntai \\ 1)Azwar.saihani63@yahoo.com \\ ${ }^{2}$ )hapizah@gmail.com
}

\begin{abstract}
ABSTRAK
Tujuan Penelitian (i) mengetahui gambaran umum industri tape ketan skala rumah tangga di Desa Sungai Karias Kecamatan Amuntai Tengah Kabupaten Hulu Sungai Utara (ii) menghitung dan menganalisis besarnya nilai tambah pengolahan beras ketan menjadi tape ketan yang dihasilkan industri rumah tangga tape ketan di Desa Sungai Karias Kecamatan Amuntai Tengah Kabupaten Hulu Sungai Utara (iii) mengetahui tingkat efisiensi industri rumah tangga tape ketan di Desa Sungai Karias Kecamatan Amuntai Tengah Kabupaten Hulu Sungai Utara. Metode yang dipakai dalam penelitian ini adalah metode sensus dan wawancara. Penelitian ini dilaksanakan mulai tanggal 24 Mei - Juli 2015. Analisis data yang digunakan adalah analisis kualitatif untuk mendapatkan gambaran kondisi umum industri tape ketan yang diolah secara deskriptif. Analisis kuantitatif menggunakan analisis biaya, pendapatan, laba, nilai tambah, dan analisis efisiensi bisnis. Alat analisis nilai tambah adalah metode Hayami. Hasil penelitian ini menunjukkan bahwa total biaya yang dikeluarkan adalah Rp.170.018, -, rata-rata pendapatan industri tape ketan dalam sekali proses produksi adalah $R p .341 .712$, -, keuntungannya adalah Rp.171.694, -, nilai tambah yang diperoleh berdasarkan pada perhitungan metode Hayami yaitu Rp.15.574,7 per kilogram bahan baku beras ketan atau 51,83\% dari nilai produksi, dan efisiensi yang diperoleh 2,00 itu artinya industri tape ketan efisien karena nilainya lebih dari 1 . $R / C$ rasio 2,00 yang berarti setiap biaya Rpl,00 yang dikeluarkan dalam industri tape ketan akan memberikan pendapatan 2,00 kali dari biaya yang dikeluarkan.
\end{abstract}

Kata Kunci : Tape, ketan,rumah, tangga, tambah.

\section{ABSTRACT}

The aim of this research is to determine the general description of home industry sticky tape seen from the characteristics of respondents and the views of the business production system, analyze the added value of sticky tape and analyze the efficiency of home industry sticky tape in Sungai Karias Village Amuntai Tengah District Hulu Sungai Utara Regency. Method research used is cencus method, the mothod of data collection uses interviews. Data collection was conducted from May until July 2015. The data analysis used is qualitative analysis to get general condition description of sticky tape industry processed descriptively. Quantitative analysis uses analysis of costs, revenues, profits, value-added and business efficiency analysis. Analysis tool of added value is Hayami method. The results of this study showed that the total cost incurred is Rp.170.018,-, the average of revenue home industry sticky tape in once process production is Rp.341.712,-, the profits is Rp.171.694,-, added value obtained based on calculation Hayami method that is Rp.15.574,7 per kilogram of raw materials glutinous rice or 51,83\% of the production value, and efficiencies obtained 2,00 that means the home industry sticky tape is efficient because the value more than $1 . R / C$ ratio of 2,00 that means every $R p .1,00$ cost incurred in home industry sticky tape will provide revenue 2,00 times of costs that incurred.

Keywords: Tape, sticky rice, house, stairs, added. 


\section{PENDAHULUAN}

Dalam setiap industri, baik industri besar maupun industri kecil-menengah skala rumah tangga selain melakukan pengolahan, tujuan utamanya yaitu untuk mendapatkan nilai tambah. Berdasarkan data BPS, nilai tambah pelaku bisnis sektor industri mikro pada tahun 2014 mencapai $\mathrm{Rp}$ 146,93 triliun, lebih tinggi dibandingkan posisi pada tahun 2013 yang tercatat sebesar Rp 98,52 triliun. Adapun nilai industri kecil sebesar Rp 164,18 triliun pada tahun 2014, lebih rendah dibandingkan posisi pada tahun 2013 sebesar Rp 201,02 triliun (Kompas, 2015).

Salah satu sektor industri kecil yang ada yaitu industri tape ketan skala rumah tangga yang menggunakan bahan baku beras ketan. Industri ini merupakan industri yang mampu memberikan keuntungan dan nilai tambah bagi pelaku usaha tersebut. Beras ketan merupakan salah satu jenis bahan pangan yang dikonsumsi oleh sebagian masyarakat Indonesia. Beras ini dapat dikonsumsi sebagai nasi atau diolah menjadi tepung untuk aneka kue. Padi ketan warnanya tidak transparankarena pada permukaan berasnya terdapat zat perekat. Beras ketan seluruh bagian butirnya mengapur atau kelam, tetapi kekerasan butirnya sama denganberas bukan ketan (Triwitono, 2012).

Sentra produksi beras ketan di Indonesia hanya ada di tiga daerah seperti di Subang, Jawa Tengah dan Jawa Timur. (Pelita, 2009). Beras ketan putih banyak digunakan sebagai bahan baku kue, cake brownies, dan makanan kecil lainnya seperti tape ketan, wajik, dodol, jadah, brem dan lain-lain.

Tabel 1. Data perkembangan produksi tape ketan di Desa Sungai Karias Kecamatan Amuntai Tengah Kabupaten Hulu Sungai Utara dari tahun 2010-2014

\begin{tabular}{lcccc}
\hline \multirow{2}{*}{ Tahun } & \multicolumn{4}{c}{ Produksi Tape Ketan } \\
\cline { 2 - 5 } & $\begin{array}{c}\text { Jumlah Tenaga } \\
\text { Kerja }\end{array}$ & $\begin{array}{c}\text { Nilai Produksi } \\
(\text { Rp.000) }\end{array}$ & $\begin{array}{c}\text { Nilai Bahan } \\
\text { Baku (Rp.000) }\end{array}$ & $\begin{array}{c}\text { Harga } \\
\text { (Rp./bungkus) }\end{array}$ \\
\hline 2010 & 1 & $62.920,8$ & 19.656 & 1.160 \\
2011 & 1 & $62.920,8$ & 19.656 & 1.160 \\
2012 & 1 & $74.239,2$ & 23.348 & 1.395 \\
2013 & 1 & $84.567,6$ & 27.024 & 1.610 \\
2014 & 1 & $84.567,6$ & 27.024 & 1.610 \\
\hline
\end{tabular}

Sumber: Data Primer, 2015

Keberadaan usaha tape ketan sudah ada sejak lama dan masih bertahan hingga sekarang, tape ketan merupakan makanan olahan yang dijadikan kudapan khas di Kabupaten Hulu Sungai Utara dengan sentra usaha di Desa Sungai Karias yang memiliki ciri tape yang dibungkus dengan daun pisang, serta cara dan alat yang digunakan dalam proses pengolahan bersifat tradisional dan masih dalam skala usaha rumah tangga. Dari hasil tersebut maka perlu dilakukan penelitian pada industri rumah tangga tape ketan dengan menggunakan analisis nilai tambah dan efisiensi usaha. Tujuan Penelitian (i) mengetahui gambaran umum industri tape ketan skala rumah tangga di
Desa Sungai Karias Kecamatan Amuntai Tengah Kabupaten Hulu Sungai Utara (ii) menghitung dan menganalisis besarnya nilai tambah pengolahan beras ketan menjadi tape ketan yang dihasilkan industri rumah tangga tape ketan di Desa Sungai Karias Kecamatan Amuntai Tengah Kabupaten Hulu Sungai Utara (iii) mengetahui tingkat efisiensi industri rumah tangga tape ketan di Desa Sungai Karias Kecamatan Amuntai Tengah Kabupaten Hulu Sungai Utara.

\section{METODE PENELITIAN}

\section{Tempat dan Waktu}


Penelitian ini dilaksanakan pada industri rumah tangga tape ketan bertempat di Desa Sungai Karias Kecamatan Amuntai Tengah Kabupaten Hulu Sungai Utara. Penelitian ini dilaksanakan mulai tanggal 24 Mei - Juli 2015.

\section{Jenis dan Sumber Data}

Data yang dikumpulkan dalam penelitian ini berupa data primer dan data sekunder Data primer yang digunakan meliputi dokumentasi, data karakteristik responden, data jumlah bahan baku yang digunakan, dan peralatan yang digunakan dalam pembuatan tape ketan. Data sekunder dapat bersumber dari pustaka dan lembaga yang terkait dengan penelitian.

\section{Metode Pengumpulan Data}

Metode yang dipakai dalam penelitian ini adalah metode sensus dan wawancara. Metode sensus yaitu dengan mengambil seluruh responden (pelaku usaha) tape ketan di Desa Sungai Karias, karena responden pengusaha tape ketan berjumlah 10 orang. Sedangkan metode wawancara adalah suatu metode penelitian dengan cara bertanya langsung kepada responden untuk memperoleh informasi yang dibutuhkan dalam penelitian. Dalam kegiatan wawancara ini peneliti menggunakan kuesioner.

\section{Metode Penelitian}

Metode yang digunakan dalam penelitian ini yaitu metode deskriptif atau survey deskriptif. Dalam mengumpulkan data digunakan teknik wawancara, dengan menggunakan schedule questionair ataupun interview guide (Nazir, 2005).

\section{Analisis Data}

Untuk melihat berapa besar nilai tambah dan seberapa efisien usaha dari proses pengolahan beras ketan sampai menjadi tape ketan maka digunakan rumus perhitungan dengan menggunakan rumus:

\section{Biaya}

Rumus untuk menghitung biaya total yaitu:

$\mathrm{TC}=\mathrm{TFC}+\mathrm{TVC}$

Dimana:

$\mathrm{TC}=$ Total biaya (total cost)

TFC = Total biaya tetap (total fixed cost)

$\mathrm{TVC}=$ Total biaya variabel (total variable cost)

\section{Penerimaan}

$\mathrm{TR}=\mathrm{Q} \times \mathrm{P}$

Dimana:

$\mathrm{TR}=$ Penerimaan total (total revenue)

$\mathrm{Q}=$ Jumlah produk yang dihasilkan

(quantity)

$\mathrm{P}=$ Harga (price)

3. Keuntungan

$\pi=\mathrm{TR}-\mathrm{TC}$

Dimana:

$\pi=$ Keuntungan

$\mathrm{TR}=$ Penerimaan total (total revenue)

$\mathrm{TC}=$ Total biaya (total cost)

\section{Analisis Nilai Tambah}

Tabel 3. Kerangka perhitungan nilai tambah metode Hayami

\begin{tabular}{ll}
\hline \multicolumn{1}{c}{ Variabel } & Nilai \\
\hline I. Output, Input dan Harga & $(1)$ \\
\hline 1. Output $(\mathrm{Kg})$ & $(2)$ \\
1. Input Bahan Baku $(\mathrm{Kg})$ & $(3)$ \\
2. Input Tenaga Kerja $(\mathrm{HOK})$ & $(4)=(1) /(2)$ \\
3. Faktor Konversi & $(5)=(3) /(2)$ \\
4. Koefisien Tenaga Kerja $(\mathrm{HOK} / \mathrm{Kg})$ & $(6)$ \\
5. Harga Output (Rp) & $(7)$ \\
6. Upah Tenaga Kerja (Rp/HOK) & \\
\hline II. Penerimaan dan Keuntungan & \\
\hline
\end{tabular}


7. Harga Bahan Baku (Rp/Kg)

8. Sumbangan Input Lain $(\mathrm{Rp} / \mathrm{Kg})$

9. Nilai Output $(\mathrm{Rp} / \mathrm{Kg})$

10. a. Nilai Tambah $(\mathrm{Rp} / \mathrm{Kg})$

b. Rasio Nilai Tambah (\%)

11. a. Pendapatan Tenaga Kerja (Rp/Kg)

b. Pangsa Tenaga Kerja (\%)

12. a. Keuntungan $(\mathrm{Rp} / \mathrm{Kg})$

b. Tingkat Keuntungan (\%)

III. Balas Jasa Pemilik Faktor Produksi

14. a. Marjin $(\mathrm{Rp} / \mathrm{Kg})$

b. Pendapatan Tenaga Kerja (\%)

c. Sumbangan Input Lain (\%)

d. Keuntungan Pengusaha (\%)
(8)

(9)

$(10)=(4) \times(6)$

$(11 a)=(10)-(9)-(8)$

$(11 \mathrm{~b})=(11 \mathrm{a} / 10) \times 100 \%$

$(12 a)=(5) \times(7)$

$(12 \mathrm{~b})=(12 \mathrm{a} / 11 \mathrm{a}) \times 100 \%$

$(13 a)=(11 a)-(12 a)$

$(13 b)=(13 a / 11 a) \times 100 \%$

Sumber: Hayami (1987)dalam Sudiyono, 2004

\section{Analisis Efisiesi Usaha}

$\mathrm{R} / \mathrm{C}$ Rasio $=\frac{T R}{T C}$

Dimana:

TR $=$ Penerimaan Total

$\mathrm{TC}=$ Biaya Total

\section{HASIL DAN PEMBAHASAN}

\section{Hasil}

\section{Penggunaan Modal Investasi}

Tabel 4. Rata-rata modal investasi pada industri rumah tangga tape ketan di daerah penelitian tahun 2015

\begin{tabular}{clcc}
\hline No & \multicolumn{1}{c}{ Investasi } & Harga (Rp,-) & Penyusutan $(\mathrm{Rp},-)$ \\
\hline 1. & Panci & 256.000 & 229,22 \\
2. & Tungku Bakar & 10.850 & 9,46 \\
3. & Karung & 2.350 & 13,1 \\
4. & Lanjung & 17.700 & 49,17 \\
5. & Nyiru & 15.850 & 44,03 \\
6. & Sendok Aduk & 2.380 & 13,2 \\
7. & Ember & 10.500 & 58,3 \\
8. & Tungku Besi & 35.000 & 30,18 \\
9. & Ulekan & 26.000 & 13,14 \\
\hline \multicolumn{2}{c}{ Jumlah } & 376.630 & 459,80 \\
\hline
\end{tabular}




\section{Analisis Biaya}

Tabel 5. Rata-rata biaya usaha pada industri rumah tangga tape ketan di daerah penelitian dalam satu kali produksi

\begin{tabular}{lccc}
\hline \multicolumn{1}{c}{ Uraian Biaya } & $\begin{array}{c}\text { Jumlah } \\
\text { Pemakaian }\end{array}$ & $\begin{array}{c}\text { Biaya } \\
(\mathrm{Rp},-)\end{array}$ & Persentase (\%) \\
\hline 1. Biaya Variabel & & & \\
a. Beras Ketan (Kg) & 10,24 & 114.400 & 67,28 \\
b. Ragi (Bungkus) & 0,53 & 3.610 & 2,12 \\
c. Daun Katuk (Liter) & 0,675 & 5.043 & 2,97 \\
d. Daun Pisang (Tangkai) & 16,6 & 16.600 & 9,8 \\
e. Kayu Bakar (Potong) & 24,2 & 7.260 & 4,27 \\
f. Lidi & & 63,6 & 0,04 \\
g. Air & & 425 & 0,25 \\
h. Biaya Transportasi (Rp) & & 15.000 & 8,8 \\
\hline Jumlah Biaya Variabel (Rp) & 52,245 & 162.402 & $(95,5)$ \\
\hline 2. Biaya Tetap & & & \\
a. TKDK (Rp/HOK) & 1,4 & 7.156 & 4,2 \\
b. Biaya penyusutan (Rp) & 459,80 & 459,80 & 0,27 \\
\hline Jumlah Biaya Tetap (Rp) & 461,2 & 7.616 & $(4,5)$ \\
\hline Total Biaya (Rp) & $1.224,645$ & 170.018 & 100 \\
\hline
\end{tabular}

\section{Analisis Penerimaan dan Keuntungan}

Tabel 6. Rata-rata produksi dan penerimaan pada industri rumah tangga tape ketan di daerah penelitian dalam satu kali produksi

\begin{tabular}{cccc}
\hline Uraian & $\begin{array}{c}\text { Rata-rata Produksi } \\
\text { (Bungkus/Hari) }\end{array}$ & $\begin{array}{c}\text { Harga Tape } \\
(\mathrm{Rp} / \text { Hari })\end{array}$ & Total Penerimaan (Rp) \\
\hline Tape Ketan & 180,8 & 1.890 & 341.712 \\
\hline \multicolumn{3}{c}{ Total Biaya $(\mathrm{Rp})$} & 170.018 \\
\hline & Keuntungan $(\mathrm{Rp})$ & 171.694 \\
\hline
\end{tabular}




\section{Analisis Nilai Tambah}

Tabel 7. Analisis nilai tambah metode hayami pada industri rumah tangga tape ketan di daerah penelitian dalam satu kali produksi

\begin{tabular}{|c|c|c|}
\hline \multirow{2}{*}{$\begin{array}{l}\text { Variabel } \\
\text { I.Output, Input dan Harga }\end{array}$} & \multicolumn{2}{|l|}{ Nilai } \\
\hline & & \\
\hline 1.Output $(\mathrm{Kg})$ & (1) & 18,502 \\
\hline 2. Input Bahan Baku (Kg) & (2) & 10,24 \\
\hline 3. Input Tenaga Kerja (HOK) & (3) & 1,4 \\
\hline 4. Faktor Konversi & $(4)=(1) /(2)$ & 1,807 \\
\hline 5. Koefisien Tenaga Kerja (HOK/Kg) & $(5)=(3) /(2)$ & 0,14 \\
\hline 1. Harga Output (Rp) & (6) & 16.630 \\
\hline 2. Upah Tenaga Kerja (Rp/HOK) & (7) & 7.156 \\
\hline \multicolumn{3}{|l|}{ II. Penerimaan dan Keuntungan } \\
\hline 3. Harga Bahan Baku (Rp/Kg) & (8) & 11.250 \\
\hline 4. Sumbangan Input Lain (Rp/Kg) & (9) & 3.223 \\
\hline 5. Nilai Output $(\mathrm{Rp} / \mathrm{Kg})$ & $(10)=(4) \times(6)$ & $30.047,7$ \\
\hline 6. a. Nilai Tambah $(\mathrm{Rp} / \mathrm{Kg})$ & $(11 a)=(10)-(9)-(8)$ & $15.574,7$ \\
\hline a. Rasio Nilai Tambah $(\%)$ & $(11 b)=(11 \mathrm{a} / 10) \times 100 \%$ & 51,83 \\
\hline 7. a. Pendapatan Tenaga Kerja(Rp/Kg) & $(12 a)=(5) \times(7)$ & 978,36 \\
\hline b. Pangsa Tenaga Kerja (\%) & $(12 b)=(12 a / 11 a) \times 100 \%$ & 6,28 \\
\hline 8. a. Keuntungan $(\mathrm{Rp} / \mathrm{Kg})$ & $(13 a)=(11 a)-(12 a)$ & $14.596,3$ \\
\hline b. Tingkat Keuntungan (\%) & $(13 b)=(13 a / 11 a) \times 100 \%$ & 93,71 \\
\hline \multicolumn{3}{|l|}{ III. Balas Jasa Pemilik Faktor Produksi } \\
\hline 14. a. Marjin $(\mathrm{Rp} / \mathrm{Kg})$ & $(14)=(10)-(8)$ & $18.797,7$ \\
\hline b. Pendapatan Tenaga Kerja (\%) & $(14 a)=(12 a / 14) \times 100 \%$ & 5,2 \\
\hline c. Sumbangan Input Lain (\%) & $(14 b)=(9 / 14) \times 100 \%$ & 17,14 \\
\hline d. Keuntungan Pengusaha (\%) & $(14 c)=(13 a / 14) \times 100 \%$ & 77,64 \\
\hline
\end{tabular}

\section{Analisis Efisiensi Usaha}

Tabel 8. Efisiensi usaha pada industri rumah tangga tape ketan di daerah penelitian dalam satu kali produksi

\begin{tabular}{llc}
\hline No & \multicolumn{1}{c}{ Uraian } & Rata-rata Per Pengusaha \\
\hline 1. & Biaya Total $(\mathrm{Rp})$ & 170.018 \\
2. & Penerimaan (Rp) & 341.712 \\
\hline & Efisiensi Usaha (R/C Rasio) & 2,00 \\
\hline
\end{tabular}

\section{Pembahasan}

Gambaran Umum Industri Rumah Tangga Tape Ketan di Desa Sungai Karias

Industri rumah tangga tape ketan di Desa Sungai Karias Kecamatan Amuntai Tengah Kabupaten Hulu Sungai Utara sudah ada sekitar tahun 1975an, umur responden pengusaha industri rumah tangga tape ketan yaitu antara 28-65 tahun dengan lama usaha dari 3 sampai 40 tahun. Kapasitas produksi tape pada industri rumah tangga tape ketan di Desa Sungai Karias rata-rata 10,24 $\mathrm{kg} /$ hari atau 57,68 $\mathrm{kg} /$ minggu atau 245,6 $\mathrm{kg} / \mathrm{bulan}$ atau 2947,2 kg/tahun. Modal investasi pengusaha tape ketan rata-rata Rp.376.630,- sedangkan penggunaan tenaga kerja rata-rata 1,4 Hok/hari atau 7,8 
Hok/minggu atau 33,2 Hok/bulan atau 398,4/tahun.

\section{Analisis Nilai Tambah}

Menurut Sudiyono (2004), faktorfaktor yang mempengaruhi nilai tambah untuk pengolahan dapat dikategorikan menjadi dua, yaitu faktor teknis dan faktor pasar. Faktor teknis yang berpengaruh adalah kapasitas produksi, jumlah bahan baku yang digunakan dan tenaga kerja. Sedang faktor pasar yang berpengaruh adalah harga output, upah tenaga kerja, harga bahan baku dan nilai input lain selain bahan bakar dan tenaga kerja.

Berdasarkan analisis nilai tambah tape ketan pada penelitian yang dilakukan di Desa Sungai Karias dilihat pada Tabel 7, dapat dijelaskan, rata-rata jumlah output yang dihasilkan sebesar 18,502 $\mathrm{kg}$ tape ketan dengan mengolah beras ketan sebanyak 10,24 kg. Dari jumlah output dan input tersebut maka didapat faktor konversi sebesar 1,807, nilai ini menunjukkan bahwa setiap pengolahan $1 \mathrm{~kg}$ beras ketan akan menghasilkan 1,807 kg tape ketan. Rata-rata tenaga kerja yang digunakan sebesar 1,4 HOK, sehingga koefisien tenaga kerja yang digunakan untuk memproduksi $1 \mathrm{~kg}$ beras ketan adalah sebesar 0,14 HOK.

Nilai tambah yang diperoleh dari tape ketan adalah sebesar Rp.15.574,7/kg. Nilai tambah ini diperoleh dari pengurangan nilai output (produksi tape ketan) dengan biaya bahan baku dan biaya bahan penunjang lainnya. Sedangkan rasio nilai tambah tape ketan adalah sebesar 51,83\%, artinya 51,83 persen dari nilai output (tape ketan) merupakan nilai tambah yang diperoleh dari pengolahan industri tape ketan.

Imbalan tenaga kerja industri tape ketan didapat dari perkalian koefisien tenaga kerja dengan nilai $0,14 \mathrm{HOK} / \mathrm{kg}$ dengan upah rata-rata tenaga kerja yaitu Rp.7156,/HOK sehingga didapat Rp.978,36/kg dan persentase imbalan tenaga kerja terhadap nilai tambah adalah $6,28 \%$. Besar keuntungan didapat dari selisih antara nilai tambah dengan imbalan tenaga kerja dengan hasil Rp.14.596,3/kg atau tingkat keuntungan sebesar $93,71 \%$ dari nilai produk. Keuntungan ini menunjukkan keuntungan total yang diperoleh dari setiap pengolahan beras ketan menjadi tape ketan.

Hasil analisis nilai tambah ini juga dapat menunjukkan marjin dari bahan baku beras ketan menjadi tape ketan yang didistribusikan kepada imbalan tenaga kerja, sumbangan input lain, dan keuntungan pengusaha. Marjin ini merupakan selisih antara nilai produk dengan harga bahan baku beras ketan per kilogram, tiap pengolahan 1 $\mathrm{kg}$ beras ketan menjadi tape ketan diperoleh marjin sebesar Rp.18.797,7/kg yang di distribusikan untuk masing-masing faktor tenaga kerja yaitu $5,2 \%$, sumbangan input lain $17,14 \%$ dan keuntungan pengusaha sebesar $77,64 \%$.

Tabel 9. Perbandingan penelitian pada industri rumah tangga tape ketan di Desa Sungai Karias dengan penelitian terdahulu

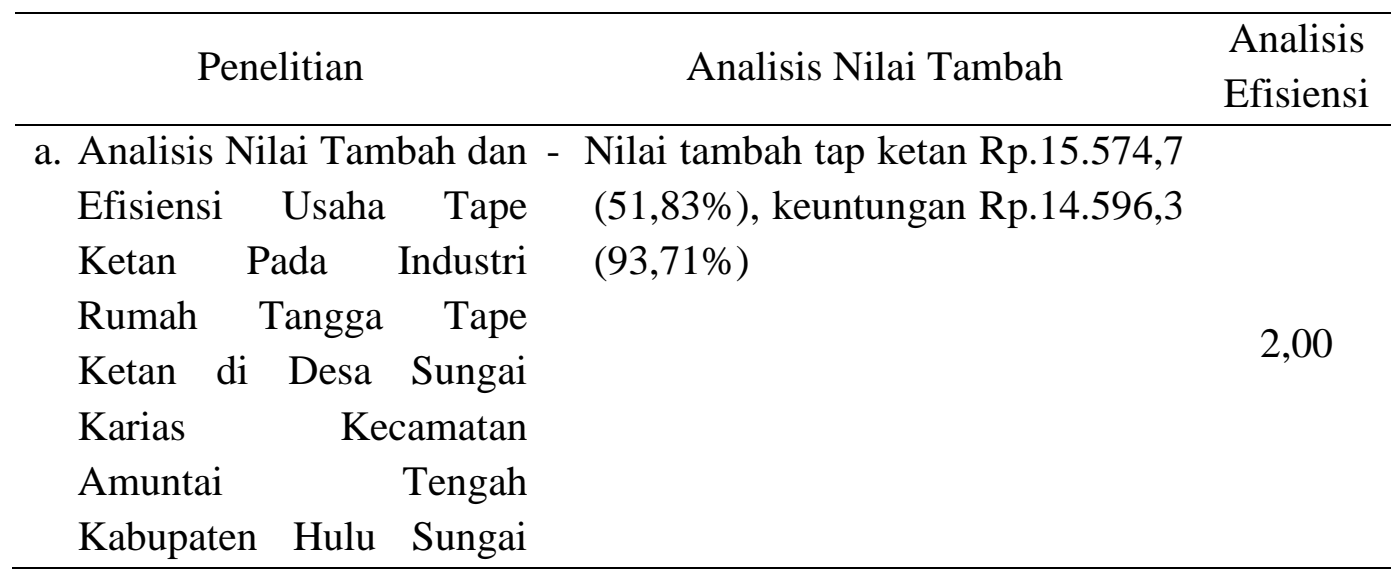




\begin{tabular}{|c|c|c|}
\hline Utara & & \\
\hline 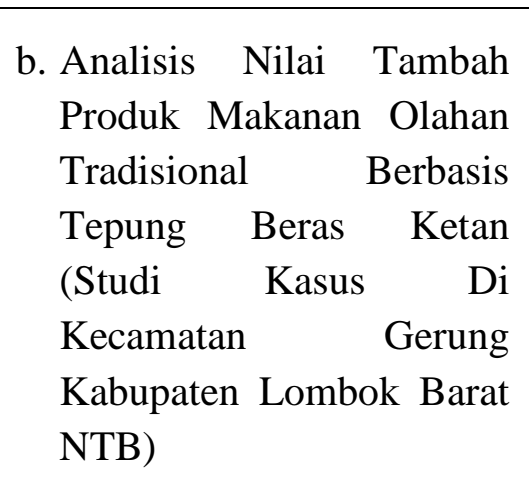 & $\begin{array}{l}\text { Nilai tambah dodol ketan } \\
\text { Rp.31.621,- }(65,3 \%) \text {, keuntungan } \\
\text { Rp.18.617,8 }(58,8 \%) \\
\text { Nilai tambah kelepon Rp.5.963,6 } \\
(35,0 \%) \text {, keuntungan Rp.1.297,- } \\
(21,7 \%) \\
\text { Nilai tambah kue cincin Rp.5.883,4 } \\
(27,7 \%) \text {, keuntungan Rp.1.883,4 } \\
(31,1 \%)\end{array}$ & \\
\hline $\begin{array}{lr} & \\
\text { c. Analisis Efisiensi dan } \\
\text { Nilai }\end{array}$ & $\begin{array}{l}\text { Nilai tambah tahu ukuran kecil } \\
\text { Rp.7.607,69 (51,49\%), keuntungan } \\
\text { Rp.3.041,07 }(39,97 \%) \\
\text { Nilai tambah tahu ukuran besar } \\
\text { Rp.5.578,80 }(43,77 \%) \text {, keuntungan } \\
\text { Rp.3.290,94 (58,99\%) }\end{array}$ & 1,39 \\
\hline $\begin{array}{lr}\text { d. Analisis Nilai Tambah dan } \\
\text { Efisiensi } & \text { Usaha } \\
\text { Agroindustri } & \text { Minyak } \\
\text { Cengkeh di } & \text { Kecamatan } \\
\text { Sawahan, } & \text { Kabupaten } \\
\text { Nganjuk } & \\
\end{array}$ & $\begin{array}{l}\text { Nilai tambah minyak cengkeh } \\
\text { Rp.904,76 (39,86\%), keuntungan } \\
\text { Rp.413,20 (45,67\%) }\end{array}$ & 1,23 \\
\hline $\begin{array}{lr}\text { e. Analisis } & \text { Efisiensi } \\
\text { Agroindustri } & \text { Kacang } \\
\text { Kedelai di Desa } & \text { Dayun } \\
\text { Kecamatan } & \text { Dayun } \\
\text { Kabupaten Siak } & \end{array}$ & $\begin{array}{l}\text { Nilai tambah tahu Rp.3.642,40 } \\
(26,98 \%) \text {, keuntungan Rp.3.616,31 } \\
(99,28 \%) \\
\text { Nilai tambah tempe Rp.3.825,18 } \\
(28,98 \%) \text {, keuntungan Rp.3.724,-- } \\
(97,82 \%)\end{array}$ & 1,24 \\
\hline $\begin{array}{lrr}\text { f. Analisis } & \text { Usaha } & \text { Industri } \\
\text { Emping } & \text { Melinjo } & \text { Skala } \\
\text { Rumah } & \text { Tangga } & \text { Di } \\
\text { Kabupaten Magetan } & \end{array}$ & & 1,17 \\
\hline
\end{tabular}

\section{Analisis Efisiensi Usaha}

Efisiensi pada industri rumah tangga tape ketan di Desa Sungai Karias sebesar 2,00 yang berarti bahwa industri tape ketan yang dijalankan sudah efisien yang ditunjukkan dengan nilai $\mathrm{R} / \mathrm{C}$ rasio lebih dari satu. R/C rasio ini menunjukkan pendapatan kotor yang diterima untuk setiap rupiah yang dikeluarkan untuk memproduksi.
Melihat perbandingan nilai efisiensi antara penelitian pada Industri Rumah Tangga Tape Ketan dengan Penelitian Terdahulu pada Tabel 9, tentunya usaha tape ketan lebih efisien dan lebih layak untuk diusahakan karena memiliki nilai perbandingan antara penerimaan dan biaya yang lebih tinggi artinya usaha tape ketan menggunakan biaya input yang lebih kecil dan mampu menghasilkan penerimaan yang besar. 


\section{KESIMPULAN}

Industri rumah tangga tape ketan di Desa Sungai Karias Kecamatan Amuntai Tengah Kabupaten Hulu Sungai Utara sudah ada sekitar tahun 1975an, umur responden pengusaha industri rumah tangga tape ketan yaitu antara 28-65 tahun dengan lama usaha dari 3 sampai 40 tahun. Kapasitas produksi tape pada industri rumah tangga tape ketan di Desa Sungai Karias rata-rata 10,24 $\mathrm{kg} / \mathrm{hari}$ atau $57,68 \mathrm{~kg} /$ minggu atau 245,6 $\mathrm{kg} / \mathrm{bulan}$ atau 2947,2 kg/tahun. Modal investasi pengusaha tape ketan rata-rata Rp.376.630,- sedangkan penggunaan tenaga kerja rata-rata 1,4 Hok/hari atau 7,8 Hok/minggu atau 33,2 Hok/bulan atau 398,4/tahun. Nilai tambah yang diperoleh dari industri rumah tangga tape ketan adalah sebesar Rp.15.574,7/kg, rasio nilai tambah tape ketan adalah sebesar 51,83\%, besar keuntungan Rp.14.596,3/kg atau tingkat keuntungan sebesar $93,71 \%$ dari nilai produk. Efisiensi Usaha pada industri rumah tangga tape ketan di Desa Sungai Karias sebesar 2,00 yang berarti bahwa industri tape ketan yang dijalankan sudah efisien, Nilai R/C rasio 2,00 berarti bahwa setiap Rp.1,00 biaya yang dikeluarkan dalam usaha industri rumah tangga tape ketan memberikan penerimaan sebesar 2,00 kali dari biaya yang telah dikeluarkan.

\section{DAFTAR PUSTAKA}

Kompas. 2015. Indonesia Siap Perbanyak Pengusaha Muda, Edisi 15 Maret 2015. Jakarta.

Nazir, M 2005. Metode Penelitian. Jakarta: Ghalia Indonesia.

Pelita. 2009. Data Produksi Beras Ketan. (http://www.pelita.or.id, diakses 11 April 2015).
Sudiyono, A. 2004. Pemasaran Pertanian. Universitas Muhammadiyah Malang. Malang.

Triwitono, P. 2012. Beras Ketan dan Sifat Fisika-Kimianya. (http://www.alatcetakrengginang.co $\underline{\mathrm{m}}$, diakses 16 Maret 2015. 